\title{
AVALIAÇÃO DA FRAGILIDADE AMBIENTAL EM ÁREA DE EXPANSÃO URBANA: O CASO DA BACIA DO CÓRREGO DO CASTELO, BAURU (SP)
}

\author{
Leonardo da Silva THOMAZINI ${ }^{1}$ \\ Cenira Maria LUPINACCI ${ }^{2}$
}

\begin{abstract}
Resumo
As estruturas urbanas se consolidam sobre um estrato que outrora era constituído essencialmente por elementos naturais, os quais regiam o espaço, impondo a morfodinâmica natural do relevo. Com a expansão das cidades, esse estrato é influenciado pela intensificação das ações antrópicas, as quais modificam a paisagem, impondo uma nova dinâmica ao relvo. Neste momento, caracterizado como período Quinário ou Tecnógeno, destaca-se a importância do estudo da fragilidade ambiental, a qual é capaz de identificar áreas mais suscetíveis a degradação diante das ações antrópicas. Este trabalho tem como objetivo analisar a fragilidade ambiental em áreas de expansão urbana, visando avaliar como as ações antrópicas atuam sobre as fragilidades do relevo. A fim de alcançar tal objetivo, foi selecionada como área de estudo a bacia hidrográfica do Córrego do Castelo, localizada no setor Norte da cidade de Bauru (SP), considerada favorável por apresentar uma acelerada expansão urbana. Para essa área foi desenvolvida a carta de Fragilidade Física e a carta de Fragilidade Ambiental, permitindo uma avaliação dos parâmetros físicos da área de estudo e da influência da urbanização sobre tais parâmetros. Assim, foi possível identificar as áreas de maior fragilidade diante da expansão urbana, constituindo um importante material de auxílio ao planejamento e gestão urbano-ambiental, fornecendo subsídios às decisões tanto no âmbito público, como privado.
\end{abstract}

Palavras-chave: Fragilidade Física e Ambiental. Relevo. Expansão Urbana.

\section{Abstract \\ Assessment of environmental fragility in urban expansion area: the watershed of the Córrego do Castelo, Bauru (SP)}

Urban structures are consolidated on a stratum that once consisted mainly of natural elements, which ruled the space, imposing the natural morphodynamics of the relief. With the cities expansion, this stratum is influenced by the intensification of anthropic actions, which alter the landscape, imposing a new dynamic to the relief. At this time, characterized as Quinary or Technogene Period, it highlights the importance of studying the environmental fragility, which is able to identify areas more susceptible to degradation in the face of anthropic actions. This work aims to analyze the environmental fragility in areas of urban expansion in order to assess how anthropic actions act on the relief weaknesses. In order to achieve this goal, the watershed of the Córrego do Castelo, located in the northern sector of the city of Bauru (SP), was selected as study area, because it presents an accelerated urban expansion. It was developed a map of Physical Fragility and a map of Environmental Fragility for that area, allowing an evaluation of the physical parameters of the study area and the influence of urbanization on such parameters. Thus, it was possible to identify the areas of greatest weakness in the face of the urban sprawl, constituting an important material to urban-environmental planning and management by providing subsidies to the decisions whether public or private.

Key words: Physical and Environmental Fragility. Relief. Urban Expansion.

\footnotetext{
1 Doutorando em Geografia pelo PPG-G da UNESP/ Rio Claro. Avenida 24 A,1515; CEP: 13506900 - Rio Claro - SP. E-mail: leosthomazini@gmail.com

2 Prof. ${ }^{a}$ Dr. a do Departamento de Planejamento territorial e Geoprocessamento - IGCE, UNESP/ Rio Claro. Avenida 24 A,1515; CEP. 13506-900 - Rio Claro - SP. E-mail: cenira@rc.unesp.br
}

GEOGRAFIA, Rio Claro, v. 42, n. 1, p. 71-87, jan./abr. 2017. 


\title{
INTRODUÇÃO
}

As questões ambientais atuais compreendem uma área de interesse da Geografia pois abarcam os sistemas físicos e socioeconômicos, interferindo na organização espacial, que para Christofoletti, (1999), compreende o objeto de estudo da Geografia. Entre as organizações espaciais, destacam-se as que estão relacionadas com os ambientes urbanos, pois se constituem numa importante forma de transformação e recriação da paisagem, onde os aspectos físicos, bióticos, sociais e econômicos interagem, formando um complexo sistema de análise geográfica.

Os assentamentos urbanos estruturam-se sobre um substrato geológicogeomorfológico, que a priori, era regido pelas leis naturais; mas a partir do momento da consolidação da urbanização, passa a ser regido pelas condicionantes antrópicas, capazes de alterar a morfodinâmica do relevo. Sobre este fenômeno, Ross (1990) salienta que:

\begin{abstract}
Nesse panorama enormemente diversificado de ambientes naturais, o homem, como ser social, interfere criando novas situações ao construir e reordenar os espaços físicos com a implantação de cidades, estradas, atividades agrícolas, instalações de barragens, retificações de canais fluviais, entre inúmeras outras. (ROSS, 1990, p. 12)
\end{abstract}

A intensidade das ações antrópicas na transformação da paisagem é tamanha a ponto de caracterizar, para alguns autores, um novo período geológico, o Quinário ou Tecnógeno (PELOGGIA, 1997, 1998) ou, ainda, o Antropoceno (CRUTZEN, 2002), onde as mudanças geológicas e geomorfológicas se dão no tempo de vida do homem.

Os estudos geomorfológicos relacionados aos ambientes urbanos no Brasil se remetem aos trabalhos de Aziz Ab'Saber (1957, 2007), os quais possuem um enfoque topográfico descritivo, exigindo, segundo Jorge (2011), amadurecimento na compreensão da ação humana sobre a morfogênese e a morfodinâmica do relevo, ou seja, a relação e os efeitos da ação humana sobre o relevo, de forma integradora.

Este pensamento, o qual salienta a ação antrópica sobre a morfogênese do relevo e sua dinâmica, irá ganhar destaque nas duas últimas décadas do século XX, tendo como referência o trabalho de Nir (1983), o qual apresenta o homem como agente geomorfológico, responsável não apenas pela transformação da paisagem, mas pela morfogênese do relevo, alterando a concepção do tempo de evolução do relevo e, consequentemente, a relação espaço-tempo da dinâmica geomorfológica, resultando no termo Antropogeomorfologia.

Assim, a Antropogeomorfologia (ou Geomorfologia Antropogênica) ressalta os estudos referentes à intervenção antrópica no meio natural e quando tais intervenções compreendem os meios urbanos, caracterizam a Antropogeomorfologia Urbana (ou Geomorfologia Urbana) (SANTOS FILHO, 2011; JORGE, 2011), que de acordo com Goudie; Viles (1997) caracteriza "uma compreensão da relação existente entre fatores do meio físico e os impactos provocados pela ocupação humana".

A esta concepção teórica-metodológica buscou-se, neste trabalho, associar os estudos referentes às unidades ecodinâmicas, apresentados por Ross (1990, 1994 e 2001), os quais buscam hierarquizar a instabilidade dos ambientes, classificando-as entre muito fraca a muito forte.

Deste modo, a relação entre os sistemas físicos e sociais, apresentada pela Geomorfologia Antropogênica (NIR, 1983) e abarcada pela Geomorfologia Urbana, é de suma importância à gestão urbana e ambiental, pois, desta forma é possível entender a intensidade de ação do homem sobre o meio físico e "compreender em que 
medida essas transformações do meio ambiente, causadas pelo homem, podem ser responsáveis pela aceleração de certos processos geomorfológicos" (GUERRA e MARÇAL, 2006, p. 29), encontrando nos estudos de Ross (1990, 1994 e 2001) um possível respaldo técnico para tais estudos.

Assim, este trabalho tem como objetivo discutir a fragilidade ambiental em áreas de expansão urbana, visando avaliar como as ações antrópicas atuam sobre as fragilidades do relevo. Para isso foi selecionada como objeto de estudo a bacia hidrográfica do Córrego do Castelo (Figura 1), localizada no setor norte da cidade de Bauru, a qual se insere no Planalto Ocidental Paulista, sobre formações geológicas do Grupo Bauru, mais especificamente as formações Adamantina e Marília (ALMEIDA FILHO, 2000). A bacia do Córrego do Castelo apresenta uma intensa transformação antrópica devido à abertura de vias de acesso à cidade e circulação de pessoas e mercadorias, propiciando a instalação de novas estruturas urbanas, como observado in loco.
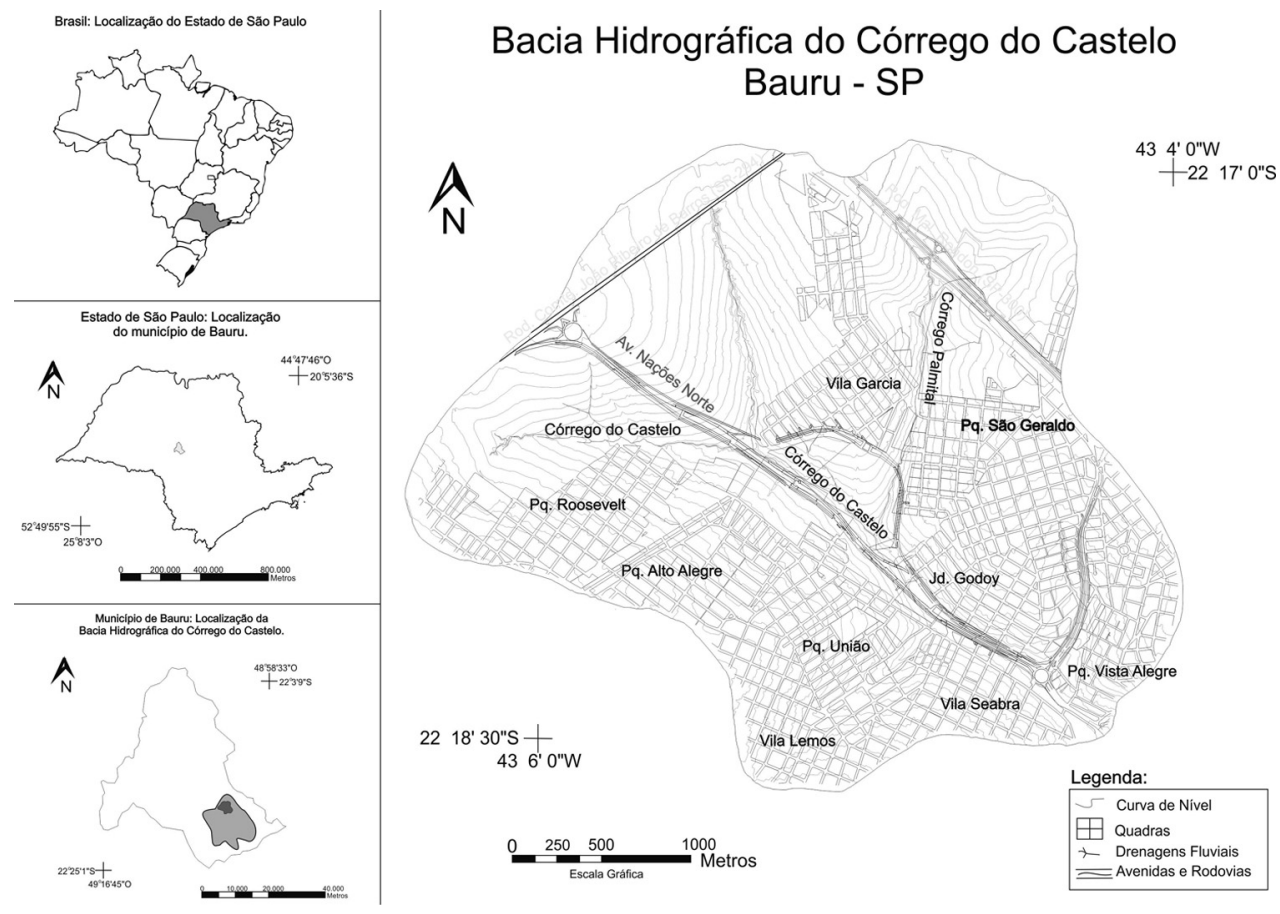

Figura 1- Localização da área de estudo

\section{MÉTODO E TÉCNICAS}

O presente trabalho pautou-se no arcabouço teórico-metodológico da Teoria dos Sistemas Complexos, o qual vem sendo utilizado nas mais diversas pesquisas geográficas e salienta a visão holística na análise científica, buscando compreender o objeto de estudo em sua totalidade, auxiliando no alcance do objetivo proposto. 
A fim de alcançar o objetivo proposto, foram confeccionados dois mapas de síntese, denominados carta de fragilidade ambiental e carta de fragilidade física, elaborados a partir dos dados obtidos com as cartas de concentração do escoamento superficial, do esboço morfo-pedológico, da cobertura vegetal, do uso e ocupação da terra e geomorfológica, com as técnicas descritas a seguir.

\section{CARTA DE CONCENTRAÇÃO DO ESCOAMENTO SUPERFICIAL}

Este material cartográfico foi confeccionado usando o software ArcGis, segundo as orientações de Fontes (2009), a qual utilizou o método de fluxo múltiplo (multiple flow), o qual permite quantificar a concentração do escoamento superficial. Este método utiliza a declividade como principal parâmetro para modelar a concentração do escoamento superficial e, devido às características da base cartográfica utilizada, foi possível mapear a concentração dos escoamentos oriundos dos arruamentos. A base cartográfica utilizada foi fornecida pela Prefeitura Municipal de Bauru e, posteriormente, vetorizada no software AutoCad, como apresentado por Thomazini (2010, 2013). Esta base cartográfica mostrou-se de suma importância por apresentar, em suas curvas de nível, as alterações topográficas criadas pelos assentamentos urbanos, tais como os aterros e cortes, permitindo assim, informações mais fidedignas das alterações antrópicas sobre o relevo.

\section{ESBOÇO MORFO-PEDOLÓGICO}

Para a confecção deste material cartográfico, buscou-se uma adaptação da cartografia geotécnica de material inconsolidado, apresentado por Zuquette e Gandolfi (2004). Como a área de estudo apresenta solos bastante espessos e não possuía dados pedológicos de detalhe, considerou-se que os materiais caracterizavam-se como retrabalhados (ZUQUETTE; GANDOLFI, 2004).

Assim, para melhor caracterizar tais materiais, foram coletadas amostras de solos em 17 pontos, distribuídos linearmente na bacia, a fim de compreender as baixas, médias e altas vertentes, com profundidades de $30 \mathrm{~cm}, 1,5 \mathrm{~m}$ e $3 \mathrm{~m}$ em cada ponto, de acordo com as orientações de Camargo et al. (2009), visando a identificação das relações texturais, mediante as características granulométricas, definidas pelo Sistema Brasileiro de Classificação de Solos (SBCS), publicado pela Embrapa (2006), o qual considera a mudança textural abrupta quando:

[...] consiste em um considerável aumento no teor de argila dentro de pequena distância na zona de transição entre o horizonte A ou E e o horizonte subjacente B. Quando o horizonte $\mathrm{A}$ ou $\mathrm{E}$ tiver menos que $200 \mathrm{~g}$ de argila/ $\mathrm{kg}$ de solo, o teor de argila do horizonte subjacente $B$, determinado em uma distância vertical $<7,5 \mathrm{~cm}$, deve ser pelo menos o dobro do conteúdo do horizonte A ou E. Quando o horizonte A ou E tiver $200 \mathrm{~g} / \mathrm{kg}$ de solo ou mais de argila, o incremento de argila no horizonte subjacente $\mathrm{B}$, determinado em uma distância vertical $<7,5 \mathrm{~cm}$, deve ser pelo menos de $200 \mathrm{~g} / \mathrm{kg}$ a mais em valor absoluto na fração terra fina (por exemplo: de $300 \mathrm{~g} / \mathrm{kg}$ para $500 \mathrm{~g} / \mathrm{kg}$, de $220 \mathrm{~g} / \mathrm{kg}$ para $420 \mathrm{~g} / \mathrm{kg})$. (EMBRAPA, 2006, p.12). 
As amostras que possuíam relação textural abrupta foram classificadas como heterogêneas e as que não possuíam, foram identificadas como homogêneas e assim, aproximando-se das orientações de Zuquette e Gandolfi (2004), quanto à definição do comportamento do solo diante das ações antrópicas e do escoamento superficial.

Assim, solos Homogêneos apresentam maiores semelhanças texturais entre seus horizontes, acarretando maior padronização na percolação das águas pluviais, grau de saturação hídrica e no escoamento de subsuperfície; já em relação aos solos Heterogêneos, devido à variação textural abrupta, apresentam discordância de saturação hídrica e percolação das águas pluviais entre os horizontes. Deste modo, os solos Heterogeneos foram considerados mais frágeis que os Homogeneos, visto que tal heterogeneidade pode facilitar a percolação horizontal da água e com isso dinamizar os processos denudativos.

\section{COBERTURA VEGETAL E USO E OCUPAÇÃO DA TERRA}

O levantamento da ocupação urbana e da ação antrópica sobre a bacia hidrográfica do Córrego do Castelo foi realizado através de estudos comparativos de pares estereoscópicos de fotografias aéreas na escala 1:10.000, datadas de 1996 (fornecidas pela Prefeitura Municipal de Bauru), com o levantamento de dados atuais em campo.

A fotointerpretação foi organizada segundo as orientações apresentadas por Ceron e Diniz (1966) quanto à identificação das formas de utilização da terra (cor, textura, forma da parcela, espaçamento e arranjo espacial), bem como os princípios fundamentais apresentados por Jensen (2011), compreendendo os "elementos de interpretação de imagem".

Após a identificação das diversas categorias de uso da terra e cobertura, estas foram classificadas pelo sistema de cores RGB (Red-Green-Blue) de acordo com o Manual Técnico de Uso da Terra (IBGE, 2006).

\section{CARTA GEOMORFOLÓGICA}

A elaboração da carta geomorfológica pautou-se na proposta dos níveis taxonômicos do relevo de Ross (1990, 1992 e 2001), sendo que, de acordo com a escala, destacaram-se os $30,40,5^{\circ}$ e $6^{\circ}$ táxons, enquadrando o mapeamento "em ordens de grandeza inferior, correspondendo às formas cujas dimensões são iguais ou inferiores a uma dezena de $\mathrm{Km}^{2}$, assumindo maior significado as formas esculturais". (ROSS, 1990, p. 53).

Associados a tais concepções, utilizaram-se também os princípios colocados por Rodrigues (2005) que salienta a representação da morfologia antropogênica, a qual se caracteriza por considerar a:

[...] própria interferência antrópica como ação geomorfológica, ação essa que pode: modificar propriedades e localização dos materiais superficiais; interferir em vetores, taxas e balanços dos processos e gerar, de forma direta e indireta, outra morfologia [...]. (Rodrigues, 2005, p. 101). 
Assim, com o intuito de representar as formas do relevo, tanto naturais quanto antrópicas, optou-se por uma simbologia diversificada e, quando necessário, adaptada.

\section{CARTA DE FRAGILIDADE AMBIENTAL}

Para a confeç̧ão deste material cartográfico, foi utilizada a proposta metodológica de Ross (1990, 1994 e 2001), sendo realizadas algumas adaptações a partir do trabalho de Silveira (2009). Tais adaptações se mostram necessárias uma vez que, para Ross (1990, 1994), as fragilidades ambientais são estabelecidas segundo o conceito de Unidades Ecodinâmicas preconizadas por Tricart (1977). Ross (1990, 1994) adapta tal conceito, definindo unidades instáveis, ou de instabilidade emergente, e estáveis, ou de instabilidade potencial. A primeira categoria refere-se aos ambientes que receberam ou recebem algum tipo de interferência antrópica, e a segunda, aos que permaneceram intocados e se configuram em seu estado primitivo. Como a área de estudo se enquadra num ambiente de expansão urbana, toda a sua extensão apresenta algum tipo de alteração antrópica, sendo, então, necessárias as adaptações recomendadas por Silveira (2009), segundo o qual não se deve utilizar o conceito de instabilidade potencial em meio urbano, mas apenas a hierarquização em classes de instabilidade emergente.

Deste modo, Ross (1990, 1994 e 2001) propõe uma classificação de instabilidade que vai desde muito fraca até muito forte, tendo como parâmetros os dados obtidos nas cartas de declividade, geomorfológicas e de cobertura vegetal e uso da terra. Além disso, a proposta do autor considera as classes de solos. Contudo, neste trabaIho foram avaliadas as condições de escoamento superficial e os dados do esboço morfo-pedológico (THOMAZINI, 2013), já que não existem dados de solos para a área, permitindo a classificação da bacia em setores com seus respectivos índices de dissecação do relevo (Dc) (Quadro 1 ).

\section{Quadro 1 - Matriz dos índices de dissecação do relevo da bacia hidrográfica do córrego do Castelo}

\begin{tabular}{c|c|c|c|c|c}
\hline \multirow{2}{*}{$\begin{array}{c}\text { Grau de } \\
\text { entalhamento } \\
\text { dos vales (m) }\end{array}$} & $\begin{array}{c}\text { Muito } \\
\text { Baixa } \\
>900 \\
(1)\end{array}$ & $\begin{array}{c}\text { Baixa } \\
700-850 \\
(2)\end{array}$ & $\begin{array}{c}\text { Média } \\
500-700 \\
(3)\end{array}$ & $\begin{array}{c}\text { Alta } \\
350-450 \\
(4)\end{array}$ & $\begin{array}{c}\text { Muito Alta } \\
<120 \\
(5)\end{array}$ \\
\hline $\begin{array}{c}\text { Muito Fraco } \\
\leq 30 \\
(1)\end{array}$ & 1.1 & 1.2 & 1.3 & 1.4 & 1.5 \\
\hline $\begin{array}{c}\text { Fraco } \\
40-50 \\
(2)\end{array}$ & $\mathbf{2 . 1}$ & 2.2 & 2.3 & 2.4 & 2.5 \\
\hline $\begin{array}{c}\text { Médio } \\
65-75 \\
(3)\end{array}$ & 3.1 & 3.2 & 3.3 & 3.4 & 3.5 \\
\hline $\begin{array}{c}\text { Forte } \\
\geq 80 \\
(4)\end{array}$ & 4.1 & 4.2 & 4.3 & 4.4 & 4.5 \\
\hline
\end{tabular}


Foram definidos valores de caráter hierárquico para as variáveis analisadas, as quais se constituíram nas unidades morfológicas da carta geomorfológica, nos solos homogêneos e heterogêneos do esboço morfo-pedológico (THOMAZINI, 2013); no escoamento superficial e no uso da terra e cobertura vegetal. Tais informações foram hierarquizadas de forma semelhante ao proposto por Ross (1990, 1994 e 2001), a fim de se proceder a classificação do grau de fragilidade.

Cabe ressaltar que não foi considerada, diretamente, a carta de declividade, pois, para a confecção da carta de escoamento superficial, a declividade é um dos parâmetros utilizados. Por essa razão, optou-se por utilizar essa carta ao invés da de declividade, ressaltando a importância da concentração do escoamento superficial proporcionado pela urbanização, tendo em vista que na base cartográfica, por meio das curvas de nível, é mapeada a ação antrópica sobre o relevo. Foi necessária, também, uma reclassificação do escoamento superficial, criando três classes as quais representam as variações desse atributo na área estudada.

Deste modo, os valores foram atribuídos de acordo com o quadro 2.

\section{Quadro 2 - Valores das variáveis utilizadas na construção da carta de Fragilidade Ambiental}

\begin{tabular}{|c|c|c|}
\hline \multicolumn{2}{|c|}{ VARIÁVEIS } & $\begin{array}{c}\text { INDICE DE } \\
\text { INSTABILIDADE }\end{array}$ \\
\hline \multirow{10}{*}{$\begin{array}{l}\text { Unidades } \\
\text { Morfológicas }\end{array}$} & (Dc 1.4) & 1 \\
\hline & (Dc 2.1) & 2 \\
\hline & (Dc 2.5) & 3 \\
\hline & (Dc 3.2) & 4 \\
\hline & (Dc 3.2) & 4 \\
\hline & (Dc 3.2) & 4 \\
\hline & (Dc 4.3) & 5 \\
\hline & (Dc 4.3) & 5 \\
\hline & (Dc 4.3) & 5 \\
\hline & (Dc 4.4) & 6 \\
\hline \multirow{2}{*}{ Solos } & Homogêneos & 5 \\
\hline & Heterogêneos & 10 \\
\hline \multirow{3}{*}{$\begin{array}{l}\text { Escoamento } \\
\text { Superficial }\end{array}$} & $0-200$ metros & 3 \\
\hline & $200-500$ metros & 6 \\
\hline & $>500$ metros & 10 \\
\hline \multirow{10}{*}{ Uso da terra } & Mata Galeria & $\mathbf{0}$ \\
\hline & Reflorestamento & 1 \\
\hline & Urbanização Densa & 2 \\
\hline & Comércio e Serviços & 3 \\
\hline & Pasto Sujo & 5 \\
\hline & Cobertura Herbácea & 6 \\
\hline & Parque do Castelo & 7 \\
\hline & Ocupação Ribeirinha & 8 \\
\hline & Horticultura & 9 \\
\hline & Expansão Urbana & 10 \\
\hline
\end{tabular}


Assim, os valores foram atribuídos às variáveis de acordo com as condicionantes que imputem maiores fragilidades, ou seja, quanto maior e mais intensa a exposição do solo, a concentração do escoamento superficial, a heterogeneidade textural do solo e as dissecações apresentadas pela carta geomorfológica, maiores serão os índices de instabilidade. A combinação dos índices de instabilidade foi realizada mediante a sobreposição dos materiais cartográficos no software AutoCad, permitindo identificar regiões da bacia de acordo com a somatória de tais índices, gerando assim, as classes de fragilidade (Quadro 3).

\section{Quadro 3 - Classes da Fragilidade Ambiental}

\begin{tabular}{c|c}
\hline CLASSES & $\begin{array}{c}\text { INTERVALO DA } \\
\text { SOMA DAS } \\
\text { CLASSES }\end{array}$ \\
\hline FRACA & $0-16$ \\
MÉDIA & $16-24$ \\
FORTE & $24-32$ \\
\hline MUITO FORTE & $32-40$ \\
\hline
\end{tabular}

\section{CARTA DE FRAGILIDADE FÍSICA}

A confecção da carta de fragilidade física pautou-se nos mesmos princípios da carta de fragilidade ambiental, através da sobreposição das cartas geomorfológica, da concentração do escoamento superficial e do esboço morfo-pedológico. Contudo, buscou-se uma aproximação à fragilidade potencial e não apenas à emergente, uma vez que sem a variável direta da ação antrópica (uso e ocupação da terra), as sobreposições possibilitaram a identificação da fragilidade quanto às características físicas da área. Assim, as áreas foram classificadas de acordo com a mesma escala da fragilidade ambiental, porém, os valores obtidos pela soma (Quadro 4) foram diferentes por não constar a variável referente ao uso da terra.

\section{Quadro 4 - Classes da Fragilidade Física}

\begin{tabular}{c|c}
\hline CLASSES & $\begin{array}{c}\text { INTERVALO DA } \\
\text { SOMA DAS } \\
\text { CLASSES }\end{array}$ \\
\hline FRACA & $8-12$ \\
MÉDIA & $12-16$ \\
FORTE & $16-20$ \\
MUITO FORTE & $>20$ \\
\hline
\end{tabular}




\section{ANÁLISE DOS RESULTADOS}

A fim de facilitar a apresentação da análise da fragilidade ambiental, a bacia do Castelo foi dividida em 10 setores (Figura 2), os quais permitiram uma melhor compreensão dos fenômenos atuantes em cada parcela da bacia, que sob a visão holística, de acordo com a Teoria dos Sistemas Complexos, favoreceu a realização do objetivo proposto.

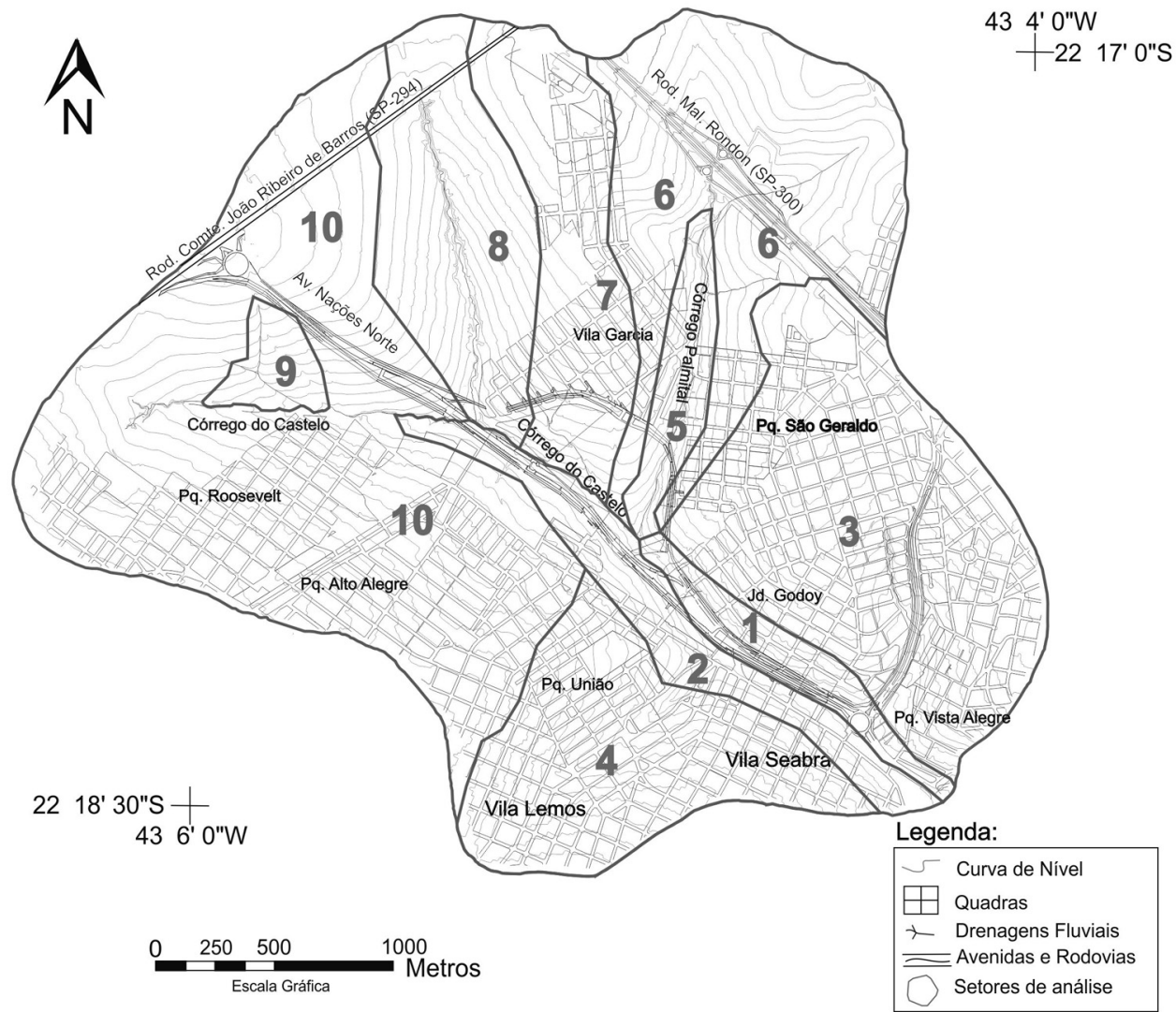

\section{Setores:}

1 - Baixa vertente do baixo curso do córrego do Castelo

2 - Baixas vertentes do baixo e médio curso do córrego do Castelo

3 - Médias, altas vertentes e topo, da margem esquerda do baixo curso do córrego do castelo

4 - Médias e altas vertentes e topo da margem direita do baixo curso do córrego do Castelo

5 - Baixas vertentes e fundo de vale do córrego Palmital

6 - Média e alta vertente e topo da micro bacia do córrego Palmital

7 - Interflúvio entre o córrego do Palmital e o afluente no alto curso da margem esquerda do córrego do Castelo

8 - Médias e baixas vertentes e fundo de vale do afluente da margem esquerda do alto curso do córrego do Castelo

9 - Setor dissecado do alto curso do córrego do Castelo drenado por afluentes

10 - Topo próximo a Rodovia Com. João Ribeiro de Barros (SP - 294),

nascente do córrego do Castelo e vertentes da margem direita até o médio curso

Figura 2 - Divisão da bacia hidrográfica do Córrego do Castelo em Setores para a análise dos resultados 
$\mathrm{Na}$ carta de fragilidade ambiental (Figura 3), a classe de maior ocorrência é a média (com $52 \%$ ), seguida pela fraca $(39,9 \%)$, forte $(7,8 \%)$ e a muito forte $(0,3 \%)$. Já na carta de fragilidade física, a classe média possui uma presença mais marcante $(62,9 \%)$, seguida da forte $(18,1 \%)$, fraca $(15,9)$ e muito forte $(3,1 \%)$. Isto ocorre porque o uso da terra vinculado a urbanização densa, cobertura herbácea, reflorestamento e mata galeria, consideradas na confecção da carta de fragilidade ambiental, concede às áreas de sua ocorrência uma proteção ao solo, diminuindo o poder abrasivo do escoamento superficial, o que não ocorre na carta de fragilidade física (Figura 4), onde tais variáveis não são consideradas.

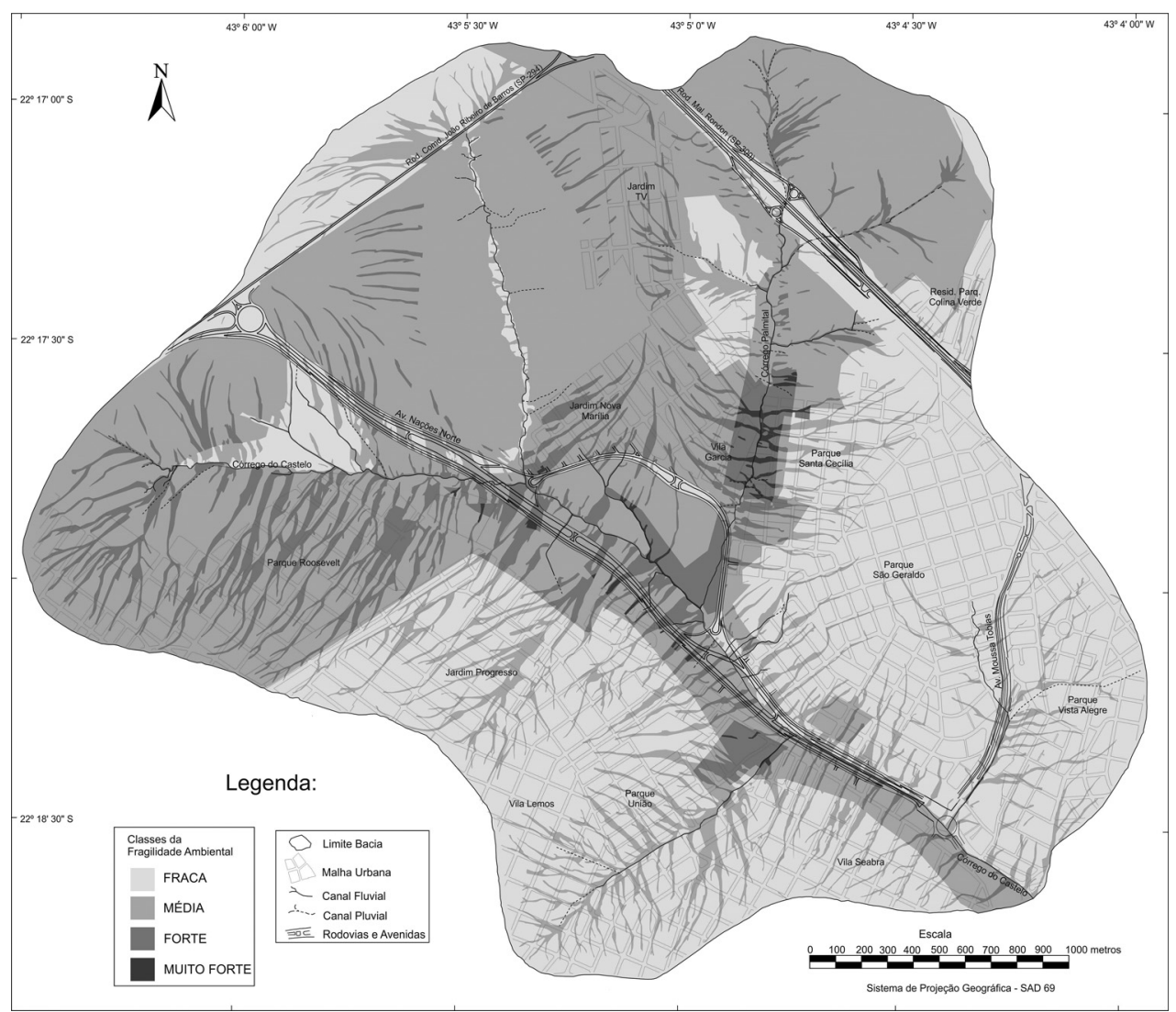

Figura 3 - Carta de Fragilidade Ambiental 


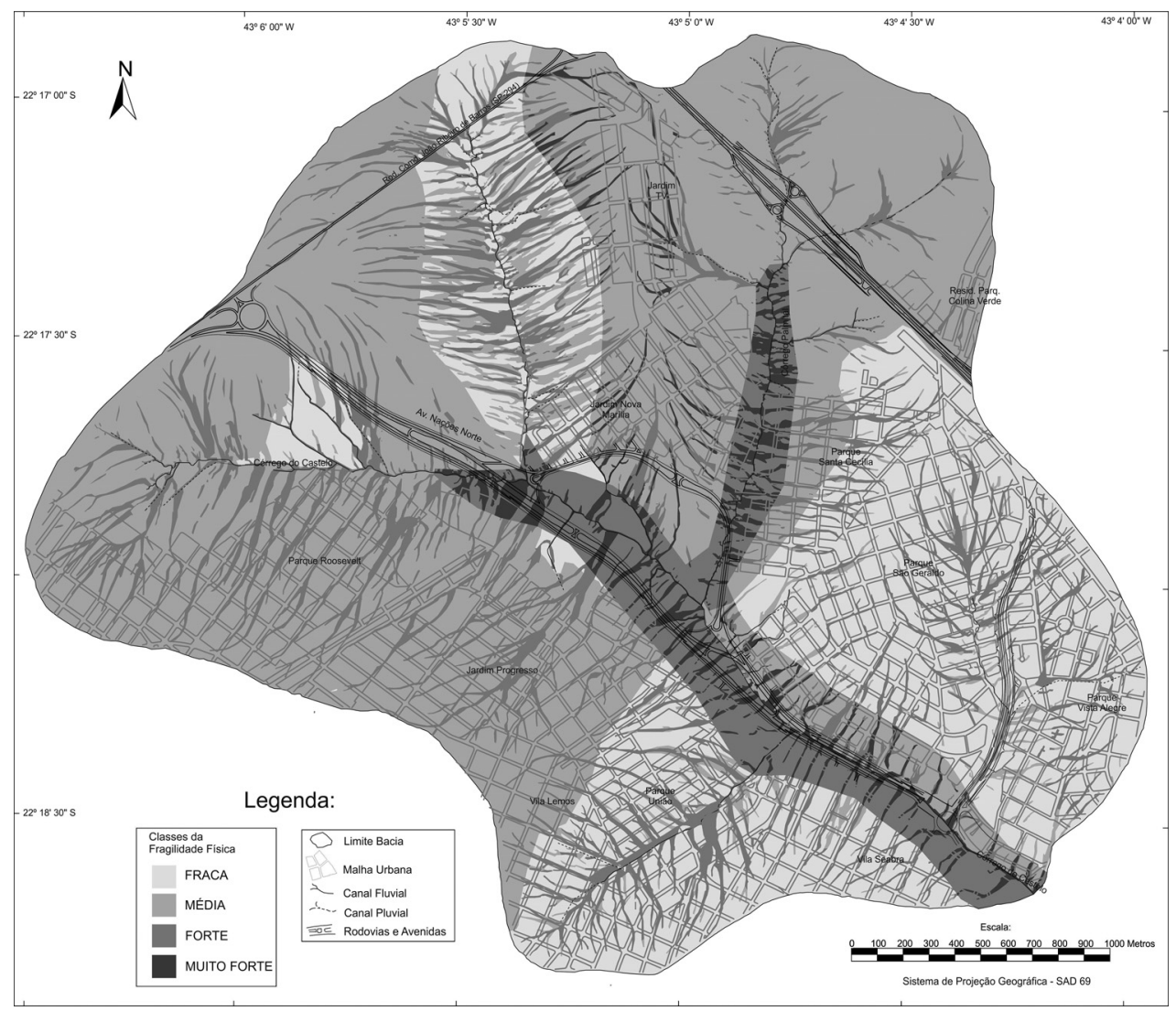

Figura 4 - Carta de Fragilidade Física

Deste modo, observa-se uma similaridade entre as cartas de fragilidade ambiental e física, à medida que as menores fragilidades se concentram da média bacia para jusante (Figuras 3 e 4). Contudo, a carta de fragilidade ambiental apresenta classe de fragilidade fraca em algumas áreas de topo devido à característica do uso da terra, sendo urbanização densa e de comércio e serviços, os quais impermeabilizam o solo, protegendo-o dos agentes intempéricos e, consequentemente, do desenvolvimento de processos erosivos de superfície.

Os setores 1 e 2, localizados em baixa vertente e fundo de vale (Figura 2), apresentam fragilidade física forte e média na maior parte de sua área e, secundariamente, mas de forma também expressiva do ponto de vista espacial, fragilidade muito forte. Tais classes de fragilidade são decorrentes dos solos com texturas heterogêneas, ou seja, maior concentração de argila nos horizontes pedológicos de sub superfície e, no caso da classe muito forte, intensa concentração do escoamento de superfície. Por se localizarem em regiões de baixa vertente e fundo de vale e com isso concentrarem o escoamento superficial advindo dos setores a montante, esse setor se mostra suscetíveis ao desenvolvimento de processos erosivos. Contudo, ao ser agregado o dado de uso da terra, obteve-se fragilidade ambiental, no setor 1 , 
com predomínio da classe fraca e, no setor 2, da classe média. Esta diferença ocorre devido à impermeabilização do solo proporcionada pela urbanização, a qual protege a superfície dos agentes erosivos, fato esse que gera a fragilidade mais fraca. Assim, uma das questões que se deve considerar na metodologia adotada nessa pesquisa, é - fato dessa não proporcionar uma análise de vizinhança, visto que, a impermeabilização dos terrenos efetuada pela urbanização gera uma concentração do escoamento superficial, cuja energia excessiva pode desencadear processos erosivos nas áreas vizinhas àquelas impermeabilizadas.

Diferentemente do setor 1 e 2, verificou-se que os setores 3 e 4 apresentam fragilidade fraca na maior parte de sua área, em ambas as cartas. Contudo, observase um aumento da fragilidade para a classe média em setores nos quais há uma intensificação da concentração do escoamento superficial, sendo tal fato mais expressivo na carta de fragilidade física. Assim, as vertentes côncavas, que concentram tal escoamento, mesmo sendo urbanizadas e teoricamente tendo os processos denudativos de superfície estancados, podem apresentar certo grau de fragilidade em função de sua forma, que propicia a concentração da água. Dessa forma, é imprescindível que tais setores tenham um eficiente sistema de drenagem urbana.

$\mathrm{Na}$ carta de fragilidade física, o setor 5 caracteriza-se pelo domínio espacial das classes forte e muito forte, sendo essa última definida em função da concentração do escoamento superficial. Contudo, assim como ocorre no setor 1 e 2, a fragilidade ambiental é amenizada devido ao uso da terra, responsável por impermeabilizar os solos. Deste modo, este setor apresenta uma fragilidade física forte e muito forte, mas, devido ao uso da terra, as ações modeladoras do relevo em superfície são amenizadas. No entanto, esse uso não inibe as ações erosivas do escoamento superficial pluvial nos setores a jusante (setores 1 e 2), bem como nas regiões (dentro do próprio setor 5 ) onde o solo não está impermeabilizado, contribuindo para o desenvolvimento dos processos erosivos em tais áreas, como demonstrado pela identificação de ravinas e voçorocas (Foto 1), in loco.

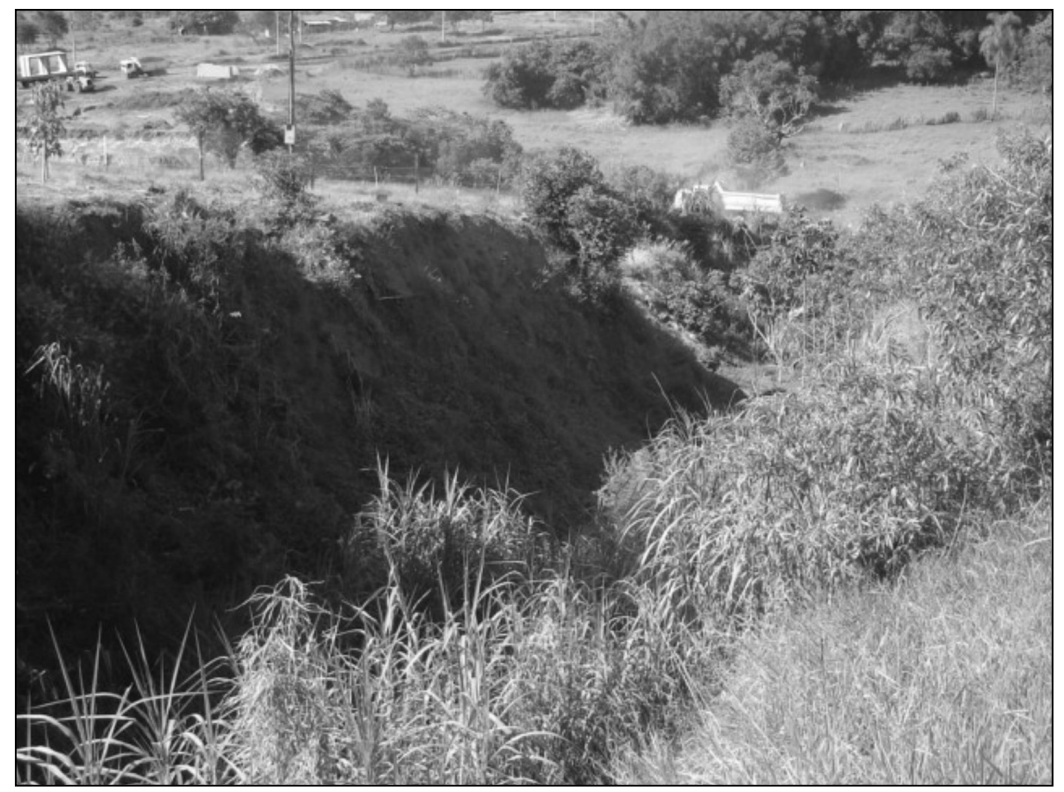

Foto 1 - Voçoroca no setor 2 
O setor 6, com predomínio da fragilidade média na carta de fragilidade física, apresenta, na carta de fragilidade ambiental, a classe fraca nas regiões de topo, devido a rodovia estadual Marechal Rondon (SP-300) e ao uso da terra ao seu entorno, destinado a implantação de atividades comerciais. A impermeabilização do solo provocada por tais usos, na metodologia adotada nessa pesquisa, leva a essa diminuição da fragilidade ambiental na área.

No setor 7, identificado como interflúvio entre o córrego Palmital e um afluente do Castelo, na carta de fragilidade física predomina a classe média e, à medida que a concentração do escoamento superficial se intensifica, aumenta a fragilidade física para forte e muito forte. Seguindo a tendência dominante, a carta de fragilidade ambiental aponta um predomínio espacial da classe média, mas a intensificação da fragilidade, provocada pela concentração do escoamento superficial, não ultrapassa a classe forte, demonstrando a influência do uso da terra, de urbanização densa e pasto sujo, nas classes de fragilidade.

O Setor 8 compreende a maior voçoroca da área (THOMAZINI, 2013), localizada na margem esquerda do alto curso do córrego do Castelo. Apresenta uma fragilidade física heterogênea, intercalando as classes fraca, média e forte, dependendo da intensidade da concentração do escoamento superficial, ou seja, quanto maior a concentração do escoamento, maior a fragilidade. Contudo, na carta da fragilidade ambiental, este setor apresenta um predomínio da fragilidade média, com presença da fragilidade fraca nas baixas vertentes e fundo de vale, onde há presença de vegetação ciliar (THOMAZINI, 2013), e no topo, próximo à rodovia Comandante João Ribeiro de Barro, (SP - 294), conhecida como Bauru - Marília, onde há menor declividade, solos homogêneos e uso da terra de comércio e serviços. Tanto as rodovias, como o comércio e os serviços, provocam a impermeabilização do solo. Esse fato, combinado as outras características físicas, pela metodologia adotada, geram classes mais baixas de fragilidade.

O predomínio da fragilidade ambiental média não impede a formação de processos erosivos avançados, denotando a interferência das áreas ao entorno, capazes de alterarem as características físicas locacionais e, assim, proporcionarem resultados não condizentes com a fragilidade ambiental, ou seja, intensa degradação em regiões de fraca ou média fragilidade ambiental.

O setor 9 apresenta similaridades de fragilidades, em ambas as cartas. Constitui-se no menor setor, mas foi necessária sua delimitação por ser uma área diferenciada do seu entorno, em função de uma rede fluvial mais densa (THOMAZINI, 2013). Contudo, apesar dessa caracterítica, apresenta fragilidade ambiental predominantemente fraca devido ao predomínio da silvicultura, solos homogêneos e baixa concentração do escoamento superficial. Os solos homogêneos, dominantemente arenosos, permitem boa infiltração das águas levando a baixa concentração do escoamento de superfície, o qual é amenizado ainda pela presença de densa silvicultura.

Já o setor 10, mesmo sendo o de maior área, mostra-se, na carta de fragilidade física, com predomínio da classe média, intercalada pela fragilidade forte, à medida que aumenta a concentração do escoamento superficial. Já na carta de fragilidade ambiental na região de topo, próxima ao setor 8 , e na vertente, próxima ao setor 4, há o predomínio da fragilidade fraca devido à presença de comércio e serviços e urbanização densa, respectivamente.

Assim, este setor caracteriza a região Noroeste e Leste da bacia, com baixas fragilidades, mostrando-se como regiões propícias à expansão urbana, como observado in loco. Contudo, cabe salientar, que as extensas vertentes deste setor, influenciam diretamente na fragilidade dos setores circundantes, principalmente os localizados a jusante. 


\section{CONSIDERAÇÕES FINAIS}

A bacia do córrego do Castelo, mesmo apresentando um predomínio das fragilidades fraca e média, possui diversos processos erosivos, inclusive uma extensa voçoroca, presente no setor 8, como demostrou Thomazini (2013). Este fato demonstra a importância da concentração do escoamento superficial e das características físicas do solo (solos homogêneos e heterogêneos), associado com os aspectos do relevo da bacia. Assim, áreas com baixa declividade, predominando a fragilidade fraca, mas com extensos interflúvios, proporcionam intensa concentração superficial das águas pluviais, podendo desenvolver processos erosivos laminares, que são intensificados diante das discordâncias texturais dos solos. Deste modo, as diferenças texturais dos solos e a concentração do escoamento superficial pluvial, mostram-se significativas na intensificação da fragilidade física e ambiental.

Estes fatos demonstram, também, a importância da análise holística, pois, os elementos que compõem um respectivo setor influenciam a morfodinâmica de outros setores, proporcionando resultados que condizem com maiores fragilidades, ou seja, o desenvolvimento de sulcos e ravinas em área de fragilidade fraca ou média, que normalmente seriam esperados em fragilidades forte ou muito forte. Como exemplo tem-se a voçoroca do setor 8 e outras na cabeceira dos afluentes do Córrego do Castelo (setor 9), os quais apresentam fragilidade média e fraca, respectivamente.

A carta de fragilidade ambiental apresenta uma área de fragilidade fraca bastante expressiva $(39,9 \%)$ devido às características do uso da terra, pois, onde o solo é impermeabilizado, como nas áreas de urbanização densa e de comércios e serviços (THOMAZINI, 2013), há uma diminuição da ação morfogênica do relevo, bem como a proteção deste das ações intempéricas, dificultando o desenvolvimento de processos erosivos.

Contudo, a concentração do escoamento superficial nestas áreas é intensificada, pois, não há a infiltração das águas pluviais, aumentando seu poder abrasivo, o que irá refletir nas áreas onde o solo não se encontra impermeabilizado. Assim, nas regiões de entorno das áreas onde o solo é impermeabilizado (principalmente nas baixas vertentes e fundos de vales), ocorrem intensos processos erosivos que dão origem a ravinas e voçorocas.

Este é o caso da maior voçoroca da bacia, presente no setor 8 , na qual a região de topo, marcada pela presença da rodovia Comandante João Ribeiro de Barros (SP294), a Bauru-Marília, e uso da terra de comércio e serviços (THOMAZINI, 2013), os quais geram solos impermeabilizados, concentram o escoamento superficial pluvial e o canalizam para a drenagem, provocando a formação da referida voçoroca.

Além do mais, cabe salientar, que a impermeabilização do solo não impede os processos de subsuperfície que podem ocorrer na bacia, mas que não foram considerados nas análises deste trabalho.

Outro fator de destaque, refere-se à expansão urbana, a qual, ao longo da história, tem evoluído da média bacia para jusante, ou seja, nas regiões que apresentam fragilidade fraca, mas atualmente, observa-se um crescimento urbano em direção às regiões de predomínio da fragilidade ambiental média e fragilidade física muito forte, nos setores 5, 6 ,7 e 10, gerando significativas alterações no relevo (Foto 2).

Portanto, mesmo a bacia possuindo o predomínio de áreas de fragilidade ambiental média e fraca, a combinação de alguns fatores, como por exemplo, diferenças texturais do solo e a concentração do escoamento superficial, provocam o aumento da fragilidade, como demonstrado pela carta de fragilidade física, dando origem a ravinas e voçorocas (THOMAZINI, 2013). 


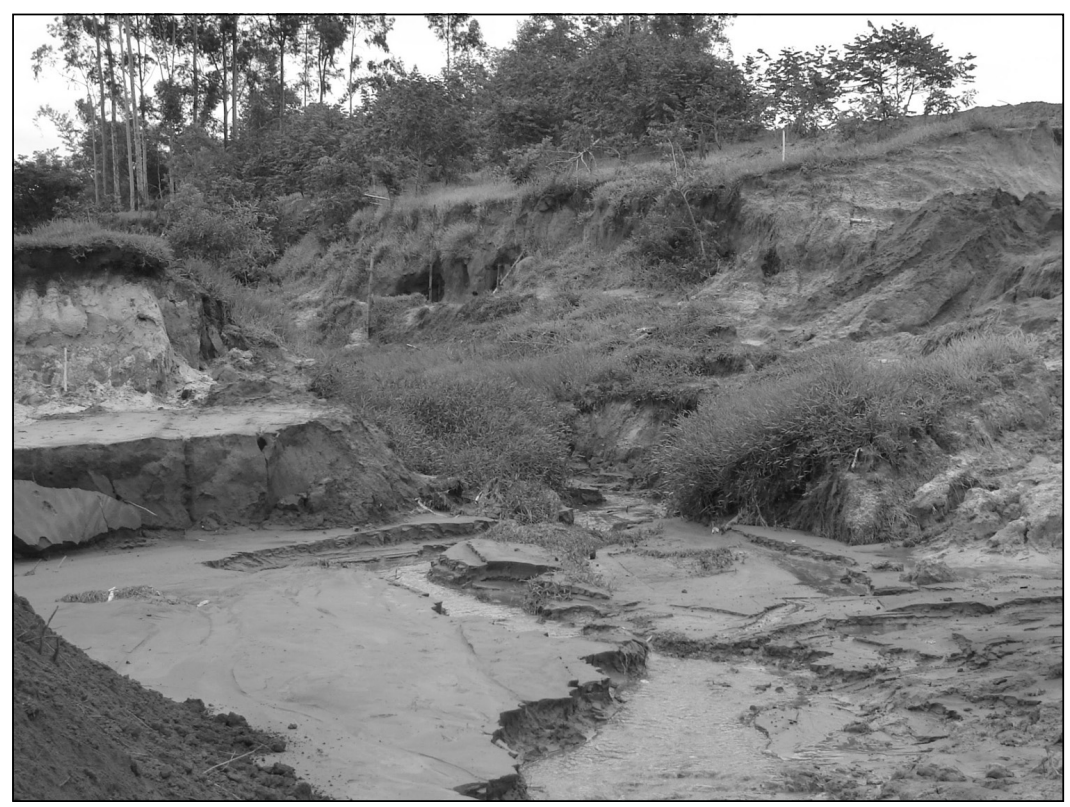

Foto 2 - Alterações topográficas no setor 10 para a construção da Avenida Nações Norte

Assim, o conhecimento do comportamento da bacia, diante de suas características físicas, pode auxiliar na formulação de políticas voltadas ao planejamento e gestão urbana-ambiental, a qual visa o desenvolvimento da cidade em concordância com a manutenção do solo, vegetação e drenagem, bem como, a prevenção de desastres com enchentes, bastante comuns na cidade de Bauru, bem como em diversas cidades do Brasil.

\section{REFERÊNCIAS}

ALMEIDA FILHO, G. S. Diagnósticos de processos erosivos lineares associados a eventos pluviosos no município de Bauru - SP. 2000. 221 f. Dissertação (Mestrado em Recursos Hídricos) - Faculdade de Engenharia Civil, Unicamp, Campinas, 2000.

AB'SÁBER, A. N. Geomorfologia do sítio urbano de São Paulo. Boletim da Faculdade de Filosofia, Ciências e Letras da USP, São Paulo, n. 219, 1957

AB'SABER, A. N. Geomorfologia do Sítio Urbano de São Paulo. Cotia: Ateliê Editorial, 2007.

CAMARGO, O. A. de; et. al. Métodos de Análise Química, Mineralógica e Física de Solos do Instituto Agronômico de Campinas. Boletim Técnico 106. Campinas: IAC, 2009. 
CERON, A.O.; DINIZ, J.A.F. O uso das fotografias aéreas na identificação das formas de utilização agrícola da terra. Revista Brasileira de Geografia, Rio de Janeiro, ano 28, n. 2, p. 161 - 173, abr./jun. 1966.

CHRISTOFOLETTI, A. Modelagem de Sistemas Ambientais. São Paulo: Edgard Blucher, 1999.

CRUTZEN, P. J. Geology of Mankind. Nature, v. 215, n. 23, 2002.

EMBRAPA. Sistema Brasileiro de Classificação de Solos. $2^{a}$ ed. Rio de Janeiro: Embrapa - SPI, 2006.

FONTES, N. Proposta Metodológica para Planejamento de Sistemas de Espaços Livres: Ribeirão Preto - SP. 194 f. Tese (Doutorado em Geografia) - Universidade Estadual Paulista, Instituto de Geociências e Ciências Exatas, Rio Claro, 2009.

GOUDIE, A.; VILES, H. The Earth Transformed - An Introdicion to Humano Impacts on the Environment. Oxford: Blackwell Publishers, 1997.

GUERRA, A. J. T. e MARÇAL, M. dos S. Geomorfologia Ambiental. Rio de Janeiro: Bertrand Brasil, 2006.

IBGE. Manual técnico de uso da Terra, 2a Ed. Rio de Janeiro, 2006. Disponível em: <Ftp://geoftp.ibge.gov.br/documentos/recursosnaturais/usodaterra/ manualusodaterra.pdf>.Acesso em: 5 dez. 2009.

JENSEN, J. R. Sensoriamento Remoto do Ambiente: Uma perspectiva em Recursos Terrestres. 2a ed. São José dos Campos: Parêntese, 2011.

JORGE, M. do C. O. Geomorfologia Urbana: Conceitos, Metodologias e Teorias. In: GUERRA, A. J. T. (Org.). Geomorfologia Urbana. Rio de Janeiro: Bertrand, 2011.

NIR, D. Man, a geomophorfological agent: An Introduction to Anthropic Geomorphology. Jerusalém: Keter Publishing House, 1983.

PELOGgiA, A. A Ação do Homem Enquanto Ponto Fundamental da Geologia do Tecnógeno: Proposição teórica básica e discussão acerca do caso do município de São Paulo. Revista Brasileira de Geociências, São Paulo, v. 27, p. 257 - 268, Set. 1997

O Homem e o Ambiente Geomorfológico. São Paulo: Xamã, 1998.

RODRIGUES, C. Morfologia Original e Morfologia Antrópica na Definição de Unidades Espaciais de Planejamento Urbano: Exemplo na metrópole paulista. Revista do Departamento de Geografia, São Paulo, n. 17, p. 101 - 111. 2005.

ROSS, J. L. S. Análise Empírica da Fragilidade dos Ambientes Naturais Antropizados. Revista do Departamento de Geografia, São Paulo, n.8, p. 63-74, 1994.

1990.

Geomorfologia, Ambiente e Planejamento. São Paulo: Ed. Contexto,

Geomorfologia e Geografia Aplicada a Gestão Territorial: Teoria e Metodologia para o Planejamento Ambiental. 2001. 322f. Tese (Livre Docência) Faculdade de Filosofia, Letras e Ciências Humanas - FFLCH, Universidade de São Paulo - USP, São Paulo, 2001.

O Registro Cartográfico dos Fatos Geomorfológicos e a Questão da Taxonomia

do Relevo. Revista do Departamento de Geografia, São Paulo, n.6, p. 17-30, 1992.

SANTOS FILHO, R. D. dos. Antropogeomorfologia Urbana. In: GUERRA, A. J. T. (Org.).

Geomorfologia Urbana. Rio de Janeiro: Bertrand, 2011. p. 227-242. 
SILVEIRA, A. Diagnóstico Ambiental do Setor Noroeste do Sítio Urbano de Piracicaba (SP): Uma Abordagem Geográfica. 178 f. Dissertação (Mestrado em Geografia) - Universidade Estadual Paulista - Instituto de Geociências e Ciências Exatas, Rio Claro, 2009.

THOMAZINI, L. da S. Análise do Relevo da bacia do Córrego do Castelo (Bauru - SP): A Influência da Urbanização nos processos erosivos. 2010 76f. Trabalho de conclusão de curso (Graduação em Geografia). Instituto de Geociências e Ciências Exatas, Universidade Estadual Paulista, Rio Claro.

THOMAZINI, L. da S. Análise da fragilidade Ambiental em área urbana: o caso da bacia hidrográfica do córrego do Castelo, Bauru (SP). 143f. Dissertação (Mestrado em Geografia) - Universidade Estadual Paulista - Instituto de Geociências e Ciências Exatas, Rio Claro, 2013.

TRICART, J. Ecodinâmica. Rio de Janeiro: IBEG - SUPREN, 1977.

ZUQUETTE, V. L.; GANDOLFI, N. Cartografia Geotécnica. São Paulo: Oficina de Textos, 2004.

Recebido em outubro de 2015 Revisado em julho de 2016 Aceito em outubro de 2016 